\title{
Empleados públicos y funcionarios: algunas ideas sobre la función pública directiva
}

\section{Francisco Javier Velázquez López *}

\section{Introducción}

En 1994, The Economist publicó "La guía del buen gurú. En ella se afirma, a propósito de Peter Drucker que, uen un terreno donde egomaníacos y vendedores de pócimas milagrosas campan por sus respetos, sigue siendo un pensador auténticon. En el marco de los temas sobre los que se van a exponer algunas ideas, la referencia a este autor es, tal vez, obligada por su acercamiento a los problemas de las grandes organizaciones, más allá de las coyunturas mediáticas o modas de extensión geográfica variable.

En buena medida, además, la intención principal del artículo descansa en la posibilidad de atraer ideas, conceptos y experiencias ajenas a las Administraciones Públicas que pudieran ser susceptibles de incorporar mejores prácticas a las organizaciones públicas. Por ello, dejando sentado la especificidad de lo público y sus limitaciones de todo tipo, el sentido de estas reflexiones no quiere ser sino camino de una posible incorporación de experiencias de éxito en otros campos.

Comenzar por el decano de los pensadores del management ha parecido necesario, por cuanto el análisis que se va a realizar se dirige a organizaciones donde el autor citado tiene algún seguidor. De la misma forma, las citas extraídas de los medios de comunicación, alguna en Internet, no intentan sino establecer un acercamiento entre nuestro tema y la imagen que de él se ve reflejada diariamente en los media. Un esfuerzo necesario y diferente al habitual, cuya loable actividad suele basarse en - la investigación de otros autores, el comentario agudo o el hallazgo feliz de conceptos u obras que no suelen ser objeto de referencia periodística.

\section{Management y transformaciones}

En la evolución de las ideas del management desde que en 1946 Peter F. Drucker publicara su Idea de la Corporación, es posible detectar una sutil pero firme evolución hacia planteamientos cada vez más cercanos a dar gran importancia a los recursos humanos. Antes de que Drucker popularizara las ideas del management, el factor determinante, al menos desde TAYLOR ${ }^{1}$, se relacionaba más con los aspectos organizativos, de distribución de los tiempos y del trabajo, logrando adelantos importantísimos para la producción industrial y el desarrollo de la sociedad capitalista, convertida hoy en el único modelo de sociedad existente tras el derrumbamiento del muro de Berlín en 1989. Un modelo único de sociedad, coincidente en sus características básicas en todos los países desarrollados, que recibe constantemente la influencia de las mismas corrientes ideológicas, desde las películas de éxito hasta los best-sellers. En nuestro campo, la situación es idéntica al menos desde los años ochenta ${ }^{2}$.

Abundan ahora quienes insisten en las ventajas del trato adecuado a los recursos humanos, quienes recuerdan que "lo más importante de la organización es su personaln, o que alientan a caminar hacia una organización de gente sabia, como co- 
rresponde a esta sociedad, denominada por algunos autores "sociedad del conocimiento". Muchas razones explican esta desviación en las prioridades científicas ${ }^{3}$. Algunas de tipo político, como la globalización ${ }^{4}$ operada en los últimos años, otras de tipo económico a partir de la mundialización de los intercambios, realidad visible desde la constitución de la Organización Mundial del Comercio, y social desde el continuo contacto entre los pueblos, la transmisión de valores comunes y la revolución operada en nuestras conciencias por medio de la televisión y la aparición masiva de los ordenadores en los hogares de los pobladores más desarrollados del mundo. Afirma SARTORI, por ejemplo, que «la televisión está produciendo una permutación, una metamorfosis que revierte en la naturaleza misma del bomo sapiens. Varias horas de televisión diaria, desde luego, conforman un individuo cuyas características no son idénticas a las del ciudadano de hace sólo cincuenta años, donde la radio y la lectura desempeñaban un papel ahora asumido por la televisión para la mayoría de las personas del mundo desarrollado.

Otras transformaciones ${ }^{5}$ deberán también operarse en el futuro, sobre todo en el ámbito económico, puesto que no parece aconsejable dejar que todas las cuestiones económicas sean reguladas únicamente por el mercado. Después de las convulsiones financieras que han tenido lugar en 1998 (Asia, Japón, Rusia, América Latina) parece ganar terreno la idea del establecimiento de algún tipo de Organismo Mundial en el ámbito financiero que regule los intercambios que por su volumen $u$ oportunismo pueden alterar sustantivamente las economías de los países. El Gobierno francés ha dado a conocer un ambicioso plan destinado precisamente a la finalidad de lograr establecer unas mínimas reglas de juego en los mercados financieros mundiales ${ }^{6}$ y tal propósito ha sido ya objeto de debate por el Grupo de los siete.

Se está produciendo en la conciencia colectiva un movimiento inverso que lleva al abandono de las tendencias neoliberales y desreguladoras y avanza un camino más cercano a la cesión de poder a los electos, a los representantes y a abandonar buena parte de los dogmas de quienes habian hecho del mercado y sus leyes la panacea universal. Si en el ámbito público esta dirección estratégica mercaderista no se tomaba en cuenta con seriedad, comienza ahora una nueva onda de pensamiento que destaca la necesidad de establecer regulaciones y normas que de forma activa establezcan reglas de juego ?

Igualmente, se detectan en Europa modos diferentes de analizar el papel del Estado y la colaboración entre los sectores público y privado. La reciente adopción de programas de reforma del Estado en Francia y el Reino Unido parecen mostrar un camino nuevo de atención a la calidad de los servicios y otros factores definidores de la relación entre Administración y ciudadanos ${ }^{8}$.
A partir de esta realidad externa, de estas condiciones del entorno, se forjan las ideas que comienzan a incidir en nuestra forma de bacer las cosas, para utilizar una fórmula particularmente querida en los últimos años para la definición de la cultura organizativa. Se habla de los trabajadores del conocimiento (DrUCKER), de la sociedad de la información, de la sociedad de flujos ${ }^{9}$, del Estado red. De ello se derivan importantes conclusiones para nuestros directivos públicos, porque como ha escrito TOFFLER '... en los viejos tiempos, cuando sólo poca gente estaba bien formada, el liderazgo de los desinformados tenia que organizarse en estructuras verticales de orden y controb.

Esta es la primera idea : las estructuras organizativas tradicionales de las Administraciones Públicas deben adecuarse a la nueva realidad. El volumen de información necesario para la adopción de cualquier decisión es tan voluminoso que es imprescindible el concurso de todos.

En todo análisis de las políticas públicas a aplicar son casi incontables las variables que han de tenerse en cuenta: legislación vigente y aplicable (estatal, autonómica o local), posición de los partidos políticos, repercusiones económicas internas (presupuestarias) y externas, identificación de la respuesta de organizaciones sociales (ONGs) y sindicatos, ánimo de los agentes internos... La complejidad existente delimita en ocasiones la imposibilidad de llevar a la práctica la acción planificada o la generación de posiciones que lindan con la incertidumbre ${ }^{10}$.

La complejidad ha sido analizada desde diferentes vertientes: como una condición de la realidad, como un obstáculo de trabajo que ha de superarse, como un elemento externo paralizante de la actividad de las organizaciones. De hecho, la descentralización es también un elemento que puede eficazmente enfrentarse con este nuevo dato de la realidad: la mirada cercana, y la actuación a pie de obra, de las Administraciones regionales y locales ", puede contribuir a la solución de numerosos problemas, aunque puede también, en ocasiones, ser vehículo de intereses particulares enfrentados con la legislación y los intereses generales. En fin, intereses generales o intereses públicos, cuya característica más acusada es, al menos hoy en España, su fragmentación: en la misma política pública actúan con igual legitimidad constitucional las Administraciones estatal, autonómica y local ${ }^{12}$.

Estamos viviendo en una época en la que las personas están informadas, saben, conocen y, probablemente, con frecuencia más de algunos asuntos que sus propios jefes. Ello lleva inevitablemente a utilizar otro tipo de técnicas organizativas y de relación. Toffler se refiere incluso con una frase a esta situación: el cambio del poder, al que describe como el hecho de que las maneras de hacer las cosas se centran en consultas y en el trabajo en colaboración, más que en el orden y. en el control. Otros autores como ClEvEland se han referido a ello como el -crepuisculo de la jerarquia, coincidiendo en el diagnóstico y en 
la necesidad de cambiar los modos de comportamiento organizativo y de relaciones humanas. La atención a la participación de los empleados es paradigmática en Ricardo Semier que llega a afirmar que ela democracia todavía tiene que entrar en los centros de trabajo.

Cada vez es más necesario destacar la importancia de otros aspectos diferentes al orden y al control, a la disciplina jerárquica y al cumplimiento estricto de las normas de comunicación burocrática, en beneficio de otros aspectos de las relaciones en el interior de las organizaciones, entre superiores y subordinados, entre servidores públicos y ciudadanos, incluyendo tener especialmente en cuenta el conflicto, la interdependencia, la negociación de soluciones y especialmente la información ${ }^{13}$.

Precisamente, en la Escuela de las Relaciones Humanas hay que buscar los antecedentes de esta fiebre "humanista" que vivimos. MASLOW y HeRTZBERG contribuyeron de forma decisiva a plantear los problemas internos de las organizaciones desde bases diferentes: centraron la cuestión en el individuo dentro de una organización y comenzaron a forjar la idea de que la organización tiene esencialmente carácter instrumental, mientras que el individuo que no está evidentemente despojado de este carácter puede constituir con claridad la diferencia, la ventaja competitiva.

De hecho, los estudios sobre el enriquecimiento del puesto de trabajo de HERTZBERG contienen numerosos aspectos cuya aplicación hoy a la Administración Pública podía ser de interés. En este sentido, ese ejercicio destacaría la utilidad de que eel jefe sólo debe intervenir cuando se le llame o de que los propios empleados "pueden controlar sus resultados y corregirse" ${ }^{14}$.

Entrando en la Administración Pública, parece que la importancia de la organización, aún mayor que en la empresa priva$\mathrm{da}$, decrece al mismo tiempo que sube enteros el desarrollo de las habilidades interpersonales. Los poderes formales de los directores generales son determinantes para alcanzar la decisión querida, pero sus posibilidades de ponerla en práctica realmente descienden considerablemente si, como ha señalado SÁNCHEZ GALLEGO, "no adquieren mayores y mejores habilidades para influir sobre las personas situadas jerárquicamente por encima y por debajo de ellos, con información en su poder que puede resultar clave..... Si además no se preocupan de tener en cuenta los verdaderos intereses de los funcionarios encargados de tomar la decisión, como ha destacado SuBIRATs, las posibilidades de éxito del proyecto decrecen claramente. ThoenIG y FriedBERG describieron este fenómeno acertadamente, concluyendo la notable importancia del poder de relación de los funcionarios con las fuerzas locales, con su entorno, que podría hacer fracasar cualquier política no deseada por los directivos ${ }^{15}$.

Aplicando estas ideas a la discusión presupuestaria en un determinado Departamento de cualquiera de las Administracio- nes Públicas podemos concluir con De VRIES, que recuerda también a otros como ZaLESNIK, LEVINSON y ELLIOT JACQUES que $l 0 \mathrm{im}$ portante son las personas, mucbo más que la interminable lista de sistemas, procedimientos y modelos que tan abundantemente aparecen en los libros de texto sobre dirección de empresas ${ }^{16}$.

Esta es la segunda idea que debe destacarse: apostar por las personas puede ser para las Administraciones Públicas un objetivo interesante porque podrá obtener frutos inmediatos, como una mayor motivación, más responsabilidad y, especialmente, concordia ${ }^{17}$ entre directivos y responsables politicos.

\section{Directivos públicos, política y Administración}

En este contexto exterior, en este entorno, especialmente complejo ${ }^{18}$ en nuestro país por su profunda descentralización política y administrativa, cobran alguna relevancia las reflexiones que se puedan realizar acerca de los directivos públicos en España, desde el punto de vista y la experiencia de quienes hemos trabajado en esta posición algunos años. Y quizás la primera es la delimitación de su ámbito de actuación: la posibilidad real de su existencia, tomando en consideración que su objeto de trabajo haya perdido razón de ser. Si la confusión entre su trabajo y el de aquellos que al servicio del partido vencedor en las elecciones no hace más que acrecentarse, podriamos preguntarnos si los directivos públicos tienen realmente un lugar, un papel específico que jugar en la Administración Pública.

Uno de los aspectos que más interesa en los tiempos actuales poner de manifiesto es de nuevo el conocido tema de la diferenciación entre política y administración ${ }^{19}$. La interpretación que se realiza de algunas leyes como las del Gobierno y la Lo. FAGE, y, sobre todo, numerosas declaraciones de los responsables públicos, en ámbitos estatales, autonómicos y locales, se ocupan de poner de manifiesto con asiduidad la preteñdida distancia. Sin negar la clara lejanía de determinadas decisiones del Gobierno de un escenario claramente administrativo, resulta, de nuevo, oportuno rememorar la íntima ligazón de ambas cuestiones. No puede dudarse que la determinación de la fecha de las elecciones o la política de nombramientos son actos de naturaleza claramente política, pero, incluso en la conformación de estas decisiones, también intervienen los directivos públicos preparando opciones diferentes, escenarios distintos o posibilidades múltiples.

Los directivos públicos, cuando realmente ejecutan trabajos estratégicos, de proposición de políticas públicas, de desarrollo de alternativas, o de gerencia de importantes recursos humanos, 
deben operar en ambientes políticos. El modelo tradicional ha intentando despolitizar lo que esencialmente es político, como ha escrito Owen E. HuGHES. "Los funcionarios trabajan diaria y constantemente en un proceso interactivo juntamente con los políticas, en un proceso llamado gestión. Desde luego, conchuye HUGHES, los politicos tienen la última palabra, pero la exclusion artificial de la Administración del proceso de elaboración de politicas ba sido finalmente descartada."

El avance de la doctrina respecto de la weberiana contraposición entre política y administración parece clara, y la insistencia en el asunto sólo serviría para enfatizar la importancia de quienes vislumbran la rígida separación entre ambas, en un momento en que la distancia es cada vez más difícil de medir. Podría ser más interesante insistir en otras tesis que inciden en la necesidad de un modelo aque tienda a la profesionalización de la alta administración, y excluya o atenúe un sistema asentado en el spoil system ${ }^{20}$.

La tercera idea que se subraya: la cercania entre directivos públicos y políticos es evidente; buscar la constante animadversión o separación rigida no es útil ni beneficiosa para nadie, sino que produce desencanto en los mejores directivos y proliferación de incompetentes en puestos de las Administraciones $P u \dot{u}$ blicas.

A ello ha de añadirse la nueva dimensión de la relación entre el ciudadano-cliente y los altos funcionarios directivos, cada vez más sensibles respecto de los grupos y ciudadanos a los que sirve, sin olvidar otros aspectos sobre los que SuBIRATS, MEndoza, Parrado y otros han escrito: los intereses de los altos funcionarios en la elaboración de las políticas públicas que, con frecuencia, pueden ser no sólo visibles sino en algún caso determinantes. La aprobación de las políticas retributivas u organizativas de grandes organizaciones públicas han estado con frecuencia más dependientes de la presión de sus servidores que de actuaciones de lobbying procedentes de ciudadanos que difícilmente consiguen aunar criterios.

Se trata de un fenómeno conocido desde que los aspectos técnicos, debido a la complejidad de las políticas públicas resultaron determinantes para el proceso de decisión. La novedad consiste en descubrir que, en ocasiones, los aspectos técnicos soportan además una importante carga corporativa o de intereses de grupos funcionariales perfectamente identificables.

Sobre la diferenciación entre política y administración son conocidas las diversas posiciones existentes que en este caso vamos a limitarnos a recordar. Sobre todas, merece la pena detenerse en la procedente de Giannini que en su conocido Informe sobre los principales problemas de la Administración del Estado de 1979, al que nos referiremos más adelante, pone las bases de una moderna concepción de la función pública que sea capaz de distinguir los aspectos funcionales de los verdade- ra y profundamente estatutarios, que como tales, merecen un régimen jurídico específico.

Ya decía Baltasar GRaClán que es una gran suerte de los poderosos acompañarse de bombres de gran entendimiento que les saquen de todos los problemas causados por la ignorancia y que incluso peleen por ellos las luchas más dificiles. Parece, hoy, una definición oportuna, porque de forma clara describe el trabajo del directivo en el mundo actual.

En mi opinión, coincidente en este punto con el de algún otro autor, debe afirmarse la posibilidad de extensión de la capa directiva en las Administraciones Públicas. Las relaciones siempre difusas, generadoras de la zona gris, los contactos entre altos funcionarios y políticos, formalmente de subordinación de los primeros respecto a los segundos, nos llevan a afirmar la legitimidad de su existencia. Preconizar la desaparición de cualquiera de los ámbitos, desde una perspectiva tecnocrática en un caso, o desde una perspectiva de hiperpolitización de la Administración, puede llevarnos a posiciones de enfrentamiento con nuestro texto constitucional. De hecho, la situación que se ha generado en algunas organizaciones públicas, como ha denunciado el Informe Nolan, refiriéndose a los quangos en el Reino Unido, ha obtenido como resultado dificultades adicionales en la prestación de los servicios, puesto que ha introducido aspectos, hasta ahora relativamente desconocidos o aislados en la función pública tradicional, como la comupción y el clientelismo ${ }^{21}$.

Las relaciones entre altos funcionarios y políticos han generado una interpenetración evidente por ambas partes. Un buen número de altos funcionarios han desarrollado puestos considerados como esencialmente políticos y en determinadas estructuras organizativas, especialmente en España en las Administraciones regionales y locales, los políticos profesionales han pasado a desempenar oficios tradicionalmente reservados al personal de carrera. Sin confundir este fenómeno con los puestos de trabajo denominados de libre designación, que en todo caso están reservados a funcionarios y cuyo contenido político es en la mayoría de los casos inexistente, es posible detectar que la apertura de puestos de contenido político a funcionarios de todas las Administraciones Públicas es otro cantar. En efecto, la determinación de esferas reservadas al ámbito funcionarial es importante, pero la amplitud de las posibilidades de cobertura de los puestos "entre funcionarios de todas las Administraciones Públicas" puede, con mayor o menor frecuencia y, sometido al buen criterio del responsable de turno, resolverse con ala búsqueda de algún militante que sea funcionarion. A veces, el hallazgo produce situaciones pintorescas.

De lo anterior se desprende otra idea, la cuarta: la necesidad de la existencia de grupos de personas especialmente preparados parael desarrollo de las funciones directivas. 


\section{Directivos y formación}

Ello nos lleva a considerar la conveniencia de la formación de los directivos, incluso en materias tradicionalmente alejadas de sus aulas de formación. Si parte del trabajo se va a desarrollar con partidos políticos, organizaciones no gubernamentales, asociaciones ciudadanas u organizaciones sindicales, el conocimiento profundo de estas organizaciones ha de formar parte de la educación cívica del alto funcionario. Ésta sería una de las características de la especificidad de la gerencia pública puesto que agerenciar en el sector público implica hacerlo en un marco de objetivos, restricciones y alternativas con disimilitudes agudas en relación con el sector privado。 ${ }^{22}$.

La situación actual, cuyas dos notas más características hacen referencia a la globalización y mundialización de los intercambios y el acelerado impulso de las nuevas tecnologías, lleva a que las condiciones esenciales del burócrata weberiano, $e l$ monopolio del conocimiento experto y su permanencia, hayan sido objeto de profundas críticas y, quizás, menores reflexiones. La unanimidad en la bondad del sistema burocrático, ideado hace más de cien años, se resquebraja; hasta ahora no se proponen grandes modelos alternativos, pero las numerosas criticas amenazan con poner en peligro el reconocimiento social e intelectual de los servidores públicos.

De hecho, otro de los asuntos que está siempre en la agenda de los responsables de los asuntos de las Administraciones Públicas es la imagen social de las instituciones y de sus servidores, elemento expresivo de la crisis de legitimidad de las instituciones que más allá de la justificación constitucional o legal, en todo caso imprescindible, buscan por medio de la eficacia, de la eficiencia y de la economía justificar su existencia. Siguiendo en este aspecto a Elke Löfrler deberíamos añadir la ética como elemento de cierre de un sistema institucional público que necesita de mejora de presencia ante la opinión de la sociedad.

Analizando las características del burócrata podemos aproximarnos a la realidad: el monopolio del conocimiento experto es hoy imposible, porque la variedad de conocimientos necesarios para, simplemente, comprender lo fundamental de cada una de las políticas públicas, no es más que una obviedad. Son necesarios ingentes cantidades de datos económicos, sociales, jurídicos, políticos, técnicos..

Pero, además, el aspecto de mayor relevancia lo constituye el hecho de que la existencia de otras instituciones fragmente el llamado interés general y aparezcan otros grupos de personas cuyo grado de conocimiento sea tan profundo o incluso superior al de los propios funcionarios. Recordemos que las grandes empresas y los bufetes de abogados cuentan con grupos de ex- perimentados especialistas en asuntos de gestión pública, cuyo conocimiento de los asuntos públicos es considerable. La referencia a las Universidades parece por otra parte obligada, dado que la colaboración académica con las Administraciones Públicas se ha incrementado, afortunadamente, durante las últimas décadas en todos los países desarrollados.

El segundo aspecto, el de la permanencia, está sometido a considerables diferencias en todos los países desarrollados: cierto es el triunfo de las ideas de la profesionalización, de la permanencia y de los métodos de selección en base a los criterios de mérito y capacidad, pero no es menos cierta la multiplicidad de regímenes organizativos o el alcance y profundidad de las llamadas diferencias entre los estratos políticos y administrativos.

Probablemente por ello, sea conveniente hoy formar a los gestores en algunos ámbitos que por su novedad pueden sorprender, pero en ningún caso se dejará de reconocer su actualidad:

1. Formar en el cambio rápido. Ha cambiado el mundo: ya no hay dos bloques, hay Internet. Cada vez están más presentes las nuevas tecnologías en los cursos de altos directivos de la Administración Pública. Algunos de ellos no habían asistido a cursos de formación desde hacía décadas. Se consideraba que ellos daban las clases, no las recibían. El mundo cambia y cambia también el trabajo de los funcionarios.

2. Formar en problemas de ciudadania. Estar absolutamente al comiente de las realidades sociales no debe constituir un bobby o ser producto de una especial preocupación por parte de los funcionarios a quienes estos temas les interesan. La base de la complejidad de las políticas públicas del fin de siglo procede de la variedad de los sujetos que en ella pueden intervenir: las Instituciones públicas, asociaciones ciudadanas, organizaciones no gubernamentales, partidos políticos, la prensa...

3. Formar en el desarrollo tecnológico. El desafío tecnológico no es sólo imparable, sino que forma parte de la realidad cotidiana. En ello ha de formarse en profundidad a los funcionarios, si no queremos que la sociedad vuelva de nuevo a la consideración de las Administraciones públicas como entes obsoletos, oscuros, ineficaces e inservibles.

Después de estas básicas reflexiones procede reflexionar sobre, por ejemplo, ¿Qué cualidades debemos fomentar? Y la respuesta es la quinta idea que se presenta: la capacidad de aprender. Aprender; siempre.

La capacidad de aprender de todo, porque el conocimiento es tan vasto que será imposible saber exactamente de qué. Es una reflexión a la que por caminos diferentes se está llegando en diferentes países y que en el especííico campo de las Admi- 
nistraciones Públicas tiene un valor considerable. Conocidas las bases del problema, lo que suele denominarse el conocimiento técnico, las habilidades de la función, procede extender entre los responsables de las políticas públicas todos los conocimientos generales que, tarde o temprano, durante la vida profesional de los funcionarios, van a tener que ser utilizados. Añadir, en suma, a los conocimientos necesarios del proceso selectivo, en las Escuelas de Funcionarios un conjunto de materias que permitan obtener una visión general de la sociedad a la que después estos mismos funcionarios han de servir.

Nada mejor que trabajar sobre el terreno para conocer adecuadamente la realidad social. Cada vez con mayor frecuencia el trabajo de las instituciones públicas se ve mediatizado, influido, criticado y, en escasas ocasiones, alabado por las organizaciones sociales. Trabajar e investigar en este campo parece imprescindible: del conocimiento de la normativa vigente o la habilidad para administrar debemos pasar a conocer la repercusión y en su caso a la evaluación de las políticas públicas. No es, además, una labor de carácter político, sino una obligación de las Administraciones públicas preparatoria e imprescindible para la decisión.

Ha de complementarse además la labor de investigación o incluso de inmersión social con la Orientación hacia los resultados: deberia existir un mayor énfasis en la realización de estudios sobre la implementación efectiva de las politicas públicas, que a menudo parecen buenas a aquellos que las formulan desde el centro decisor pero que se desvanecen de mala manera en las localidades donde se han de aplicar (WILDAVSKY). La lejanía del gestor en relación con los problemas ciertos de los ciudadanos ha sido combatida por la descentralización operada en nuestro país, pero aún debemos de valorar que, en el proceso de adopción de la decisión, han de tenerse en cuenta si los resultados, transcurrido un tiempo prudencial, mejoran la situación, equilibran las divergencias o simplemente ocupan una rúbrica en el presupuesto ${ }^{23}$.

Nada puede hacerse sin el concurso de los colaboradores, proclaman los manuales del management que demandan la proactividad de los funcionarios. El planteamiento de la pasividad en los directivos públicos no tiene ya sentido: la supervivencia de la organización, en cierta medida, está también relacionada con el abandono de la actitud pasiva y el fomento de la proactividad en la búsqueda de las mejores soluciones para el logro de los resultados perseguidos.

Acercarse a la ciudadanía, conocer el entomo del mundo que les rodea e incluso saber cómo utilizar las diferentes sensibilidades de la comunidad, aparecen como necesidades ineludibles. Las opiniones sobre los diversos temas son diferentes desde el punto de vista político, pero también desde el social, o simplemente desde los diversos organismos públicos que batallan por lograr el mejor resultado para la organización. la conclusión parece clara no se puede vivir en la eficacia indiferente: hay que conocer con detenimiento la realidad que nos rodea.

Otras características esenciales de la dirección, como la comprensión de los objetivos globales de la organización, la aptitud para dirigir equipos multidisciplinarios, la capacidad para seleccionar información relevante, comunicar o tomar decisiones en el momento apropiado deben ser igualmente objeto de desarrollo formativo. Aquí radica una de las dificultades mayores del empeño: combinar el conocimiento del específico mundo de las Administraciones Públicas con la introducción de otras técnicas de dirección de excelentes resultados en el ámbito de las organizaciones privadas.

Dice Michel Crozier que cuando se enseña así a la gente a "valorar sus cualidades individuales en un trabajo en equipo, se constata que están verdaderamente contentos de ello. Con seguridad que es uno de los aspectos que nos interesa especialmente incentivar, dado que se trata de una necesidad de nuestro tiempo, en el que la información constituye un valor de imposible postergación. La simultaneidad de las comunicaciones impone formas de trabajo, intercambios de ideas y formulas organizativas, desconocidas hasta ahora o relegadas a estructuras de funcionamiento más relacionadas con el asesoramiento que con la toma de decisiones.

Debemos desarrollar ciertas habilidades entre los funcionarios públicos, en este mundo donde la información es el requisito determinante de la acción relacionada con las políticas públicas, que fomenten, como ha señalado Toffler, obtener los resultados por medio de la persuasión, consultando con todos aquellos que tienen que bacer algo para llevar a cabo el trabajo de tomar decisiones. De aquí se deduce, y la coincidencia es general entre los estudiosos en la materia, la necesidad del trabajo en colaboración, el desarrollo de las estructuras colegiadas y, en definitiva, no basar la parte sustancial del trabajo de los entes públicos en el orden y el control.

La importancia de la formación se acrecienta, además, por la situación en la que en este momento se desarrolla nuestra actividad. De forma precisa, la actividad en las organizaciones públicas se caracteriza por un entorno complejo, cuyas dos grandes -características hacen referencia a la descentralización territorial por una parte, $y$, por otra, a la necesidad de reducir el volumen de nuestro peso en la economía nacional.

El primero de estos aspectos hace que, en buena medida, los roles de nuestros altos funcionarios se vayan modificando, adaptándose más desde el perfil de los buenos gestores que demandaba nuestra sociedad (y que en ciertos aspectos sigue demandando) hacia las funciones de guía estratégico, que de acuerdo con buena parte de los analistas de la materia le corresponde a la Administración del Estado. La complejidad de las tareas es indudablemente superior a la anterior etapa $y$ han do 
fomentarse, además de las actividades tradicionales y las habilidades correspondientes, aquellas que hacen referencia a la negociación, la motivación, la comunicación: en definitiva, la habilidad para tejer redes que permitan la solución coherente y eficaz de los asuntos públicos ${ }^{24}$.

El segundo aspecto ha sido puesto de manifiesto también de forma generalizada hasta el punto de que parece conformar el núcleo del llamado pensamiento único: la necesidad de bacer más con menos. En un mundo como el actual, la opinión publica nacional e internacional considera excesivo el gasto que las Administraciones públicas consumen. Así se manifiestan al unísono los foros internacionales y ésta parece ser la nueva idea que debemos de alguna manera aceptar, aunque la extensión del núcleo estratégico, la dimensión del Estado, en definitiva, es objeto de polémicas doctrinales y políicas, en especial desde la perspectiva de los países en desarrollo ${ }^{25}$.

En esta situación, nuestros funcionarios deben desarrollar su trabajo de otra forma, deben ser mejores, estar más capacitados, porque probablemente su actividad no va a decrecer, sino que además de hacerse más compleja va a incrementarse, como corresponde a una sociedad relacionada cada vez más con pautas de envejecimiento de población y de extensión de la demanda de nuevos servicios.

El tercer aspecto de relevancia en esta materia tiene que ver con la integración europea. Más allá de decisiones coyunturales como las que parece han supuesto un neofortalecimiento de Instituciones nacionales en detrimento de las Instituciones Comunitarias en el Consejo de Cardiff, no parece caber duda de que el futuro ha de quedar establecido sobre la base de una estrecha colaboración entre las Instituciones Comunitarias y las nacionales.

Algunos autores como DufFau llegan a afirmar que las administraciones nacionales se convertirán progresivamente en componentes de la administración europea con un régimen de competencias compartidas que se extenderá a los principales sectores de la intervención administrativa. Contamos ya con amplias experiencias en esta materia en España, en particular en lo que se refiere a la Política Agraria Común o a la administración de los Fondos de desarrollo regional.

Habrá pues en el próximo futuro, está habiendo ya, podríamos afirmar, importantes alteraciones estructurales que alcanzan no sólo el régimen competencial sino también la dimensión, el contenido y las habilidades requeridas por nuestros funcionarios públicos. En este específico cämpo es donde tiene sentido, por ejemplo, que desarrollemos actividades que potencien la habilidad negociadora, no sólo con los sübordinados o con las organizaciones sindicales, campos tradicionales del buen hacer de nuestros directivos, sino también de otros responsables de organizaciones que deben plasmar sus decisiones positivas sobre las actividades de las Administraciones nacionales.

\section{Directivos y realidad exterior}

Recientemente, otro autor, Rolando A. HEIFETz ha entrado en los asuntos relacionados con la capacidad de los directivos de analizar la realidad o en la posibilidad de que una actitud de interés en el seno de las organizaciones públicas pueda ser negar, esconder o aparcar los problemas porque resulten impopulares o molestos para el poder. Los problemas están ahí y la posible función del liderazgo de los directivos, podría afirmarse, es identificarlos y ayudar a la sociedad a afrontarlos.

Todo ello en un marco de análisis de las mejores soluciones a los problemas, de tener en cuenta las múltiples variables que inciden sobre ellos ${ }^{26}$, porque para progresar en las soluciones no se necesita que alguien dé respuestas desde lo alto, sino que cambiemos nuestras actitudes, nuestra conducta y nuestros valores. Esperar la solución de la autoridad no es adecuado (HEIFETZ, 1998). De hecho, Michel CROzier, analizando las estructuras organizativas y la relación jerárquica y de subordinación existente entre los diversos niveles y escalones administrativos, objeto de crítica literaria constante ${ }^{27}$, aún hoy la nota característica de las organizaciones públicas en todos los países, llamó la atención sobre la inadecuación entre el mundo actual y las organizaciones burocráticas clásicas: el orden de capas burocráticas superpuestas resulta demasiado engorroso para ser aplicado a la complejidad del mundo moderno ${ }^{28}$.

La necesidad de la regulación de los directivos públicos parece ponerse igualmente de manifiesto por el hecho de que continúan aumentando en la última década, y con menor ritmo en los últimos años, el número de funcionarios susceptibles de conformar el universo de los directivos públicos: En junio de 1998, su número había aumentado en más de mil respecto a las cifras oficiales existentes en 1996: 9917 frente ${ }^{29}$ a 11096. 1179 más, por tanto, según los datos del Registro Central de Personal.

Los directivos públicos deben además desarrollar su trabajo en un entorno especialmente complejo por razones políticas económicas y sociales pero la complejidad de su labor se ve de alguna forma entorpecida por su mala imagen ${ }^{30}$ y por sus costos ocultos, de escasa importancia en las organizaciones privadas. Estos costos ocultos son los costos económicos correspondientes al derroche de actividad administrativa derivado del hecho de que la función administrativa se desarrolla en forma preestablecida, con participación de órganos y oficinas. A ello habría que añadir probablemente el coste de la participación social que extiende el período de la decisión hasta límites incomprensibles desde el punto de vista de la gestión moderna. 
¿Puede comprenderse hoy, en la era de Internet, que tomada la decisión de acometer la construcción de una importante obra pública ésta sólo pueda ser finalizada en el mejor de los casos seis años después? Con toda rotundidad no, pero este tiempo es imprescindible, si se quiere observar la otra obligación de cumplimiento de los plazos legales necesarios para la objetividad y la imparcialidad. La última modificación de la Ley de Contratos del Estado extrema las disposiciones que garantizan el fiel cumplimiento de todos los aspectos formales en detrimento de la celeridad o eficacia del proceso, aspecto en el que existió unanimidad política en los grupos parlamentarios del Congreso de los Diputados ${ }^{31}$. El cumplimiento de las garantías y plazos se ha visto reforzado pero, internamente, los altos funcionarios han visto, una vez más, complicarse su trabajo.

Ésta es la sexta idea: la complejidad del trabajo de los directivos públicos aumenta y la mirada de la sociedad bacia ellos es cada vez más atenta y exigente.

\section{Funcionarios y negociación colectiva}

Otro de los aspectos que tendría interés poner de manifiesto es la relación entre las relaciones de servicio en los ámbitos público y privado: en buena medida ha de coincidirse con Giannini en que "los ingenieros, los contables, los archiveros del Estado desarrollan la misma actividad que realizarian en una empresa privada. Algunos de estos funcionarios añaden a esta relación de servicio una relación funcional y en calidad de tales realizan actos de autoridad, de poder público. Por ello, en mi opinión quedan plenamente vigentes las afirmaciones del Informe Giannini cuando expresó que ‘ Yabrá que preguntarse abora si no será otro posible camino abierto el de la privatización de las relaciones laborales con el Estado cuando éstas no estén vinculadas al ejercicio del poder público, conservando como relación de Derecho puiblico las de aquellos a quienes tal ejercicio les está o pueda estarles confiado, es decir los actuales directivas y dirigentes.

En efecto, en Italia desde las modificaciones operadas en 1993 se han constituido dos grupos de directivos que constituyen la máxima escala funcionarial y que en el caso de los dirigentes generales son los únicos cuyo estatuto jurídico está sometido al régimen estatutario ${ }^{32}$, siendo el resto de los trabajadores del sector público sometidos al Derecho laboral. No se trata ahora de estudiar el régimen funcionarial italiano, sujeto especialmente a vaivenes políticos, pero tiene interés recordar que contiene elementos de singular importancia para el tema que nos ocupa, como la atribución de potestades de decisión propias y no avocables por la autoridad política en materia de contratación, régimen de personali', edificios, etc.
Conviene ahora plasmar algunos interrogantes en la política dirigida a los directivos que contiene la situación actual. Recordemos algunos datos relevantes que definen la realidad.

El primer elemento es que la tradición en relación con los empleados públicos en España es el reconocimiento, su trayectoria de régimen estatutario. De hecho, la referencia a su selección por el sistema de mérito y capacidad se halla recogido en numerosas Constituciones españolas, además de la actual, y en concreto en las de 1837, 1869, 1876 y 1931.

El segundo elemento es la constatación de que, después de la Ley de funcionarios de 1964, se produjo un proceso de laboralización de la función pública que se acentuó tras la aprobación de la Ley de Medidas para la Reforma de la Función Pública de 1984 y que alcanza en la actualidad a 107.000 personas en el ámbito de la Administración General del Estado. La situación ha hecho exclamar a Alberto Palomar que de seguir así el número de los regidos por el Derecho del trabajo será superior a los que están sometidos al Derecho administrativo.

El proceso de laboralización de la función pública, combinado con la sentencia del Tribunal Constitucional sobre la Ley de Medidas y, en concreto sobre el artículo $15^{33}$, ha hecho entrar en vigor todo un proceso de "funcionarización" que ha supuesto la realización de pruebas en la mayoría de los ministerios y organismos, para reconvertir a todo este personal, dado que desempenaban en la práctica labores consideradas de funcionarios y cuyo número alcanzará 29.000 personas en la Administración del Estado. La conclusión no puede ser otra que la ya señalada por ENTRENA CueSTA: "estamos en una tendencia a la contractualización de la función pública".

El tercer elemento sobre el que conviene llamar la atención se refiere al acentuado proceso de negociación colectiva que ha tenido lugar en la mayoría de los países europeos y en particular en Espana desde la aprobación de la Constiución de 1978. Este proceso, de tintes más profundos incluso en determinadas organizaciones públicas, como en el País Vasco o en los Acuerdos firmados en numerosos Ayuntamientos como los de Madrid y Barcelona (en especial), ha alterado sustantivamente la forma en que se deben ver las relaciones de trabajo estatuarias o de servicio en las Administraciones Públicas.

El primero de estos acuerdos en la Administración General del Estado, firmado en 1983, inicia un camino continuado más tarde por los acuerdos de 1991 y 1994 y más recientemente por el de 1998, que establecen condiciones de trabajo para la totalidad de los funcionarios públicos. Es un camino real, con evidentes resultados positivos, que contractualiza la función pública: los acuerdos firmados entre las Administraciones Públicas alteran sistemáticamente el régimen estatutario de los funcionarios priblicos. Son, además, el vehículo de las modificaciones más importantes y, sin el requisito previo de la negociación, consensuada o no, no parece 
que sea posible, ni conveniente desde un planteamiento democrático, avanzar en cuestiones de función pública en España, con independencia del partido político gobernante.

Esta situación pernite plàntearse con seriedad para España otras tesis en torno a la función pública directiva, diferentes a las usuales en este campo. Si, por una parte, la sentencia del Tribunal Constitucional obliga a la funcionarización de un buen número de saborales. y, por otra, las Organizaciones Sindicales presionan para alterar anualmente (o cada cierto período de tiempo) el estatuto funcionarial, puede que sea necesario comenzar a distinguir entre el personal directivo, sometido a un régimen de función pública y el resto del personal que debería vincularse mediante técnicas contractuales, respetando el artículo 103.3 de la Constitución española. Algunos autores como BRESSER ${ }^{34}$ están ya defendiendo tesis similares distinguiendo entre quienes desarrollan afunciones de soberanía, autoridad o intervención administrativa," o "funciones estatales de orden superior, núcleo estratégico o funciones exclusivas del Estado para la provisión de bienes públicos puros" y aquellos otros cuya función esencial es la prestación de servicios a los ciudadanos, donde los elementos conformadores del management y de la eficacia y la eficiencia puedan desarrollarse puesto que se trata de la producción de bienes y servicios no exclusivos o para el mercado ${ }^{35}$.

Ésta es la séptima idea: la diferenciación ${ }^{36}$ en el régimen juridico y retributivo entre los directivos y el resto de los funcionarios se está produciendo en la realidad. Cada año son más los funcionarios que abandonan el régimen juridico "tradicional para pasar al de su Ente, Entidad Püblica Empresarial o Agencia.

\section{Directivos, lo público y lo privado}

Otro de los aspectos en que se ha de insistir es el de la relevancia de los aspectos éticos de los directivos públicos, estableciendo determinados controles que refuercen su independencia y profesionalidad, y las garantías de la necesaria imparcialidad. Algunas sugerencias en este sentido podrían ser objeto de estudio y, en su caso, aplicación en determinados sectores:

- Dividir los procesos de índole económica en varias fases.

- Establecer la obligatoriedad de que las decisiones importantes sean adoptadas por más de una persona.

- La rotación de los directivos en los puestos más importantes.

- La presentación obligatoria y periódica de declaraciones de bienes y derechos de los que sean titulares los funcionarios directivos.
La Segunda Conferencia de los Servicios para la Lucha Contra la Corrupción del Consejo de Europa ha llamado la atención sobre estos temas y ha advertido que los sobornos y las extorsiones en las Administraciones de los Estados han sobrepasado el marco de las conductas puramente individuales, llegando a ser una causa de deterioro sistemático de los presupuestos públicos. Tendría, en nuestra opinión, particular interés, insistir en la conducta ética por parte de los responsables de la toma de decisiones y, en especial, de aquellos a quienes encomendamos la gestión de los asuntos públicos puesto que, como ha recordado Crosby, el mejor atributo de un líder (o de un directivo público diríamos nosotros) consiste en mostrar una conducta ética en cualquier circunstancia.

Desde el punto de vista de las cualidades que deben tener nuestros directivos públicos, destaca Adela CorTina que el futuro en continuo cambio nos exige flexibilidad y que, en consecuencia, el éxito en la organización del mañana está en ser capaz de desarrollar organizaciones para las personas y sus capacidades y no personas para una organización. Desde una perspectiva singular, CORTINa rescata valores éticos del postaylorysmo, en el que reconoce posiciones cercanas al fomento de relaciones de cooperación, frente al conflicto, el recurso a la creación y no a la chapuzan, señalando, en consecuencia, posibilidades de fomento de cualidades en las organizaciones, no coincidentes con las tradicionales. Incluso destaca la capacidad de la formación en nuevos valores, en una cultura organizativa diferente que podría generar posibilidades de éxito en las organizaciones ${ }^{37}$.

Esta tesis parece ser coincidente con otras como las de BARZFLAY y otros, que ponen el acento en el paradigma de una nueva Administración pública basada en estructuras mucho más flexibles en la orientación hacia los ciudadanos y, finalmente, en la atención al capital humano interno de las organizaciones. públicas, a las personas ${ }^{38}$.

Parafraseando a GaRCíA ECHEVARRía podría afirmarse que si la figura del directivo constituye la encrucijada en todo el diseño económico de un país, en el sector público ello constituye una necesidad ineludible: las transformaciones operadas en nuestro Estado, en el entorno con el que tienen que trabajar los directivos públicos han sido si cabe más profundas que las que ha tenido que soportar el directivo de la empresa privada. Si éste vive en el continuo cambio, el directivo público vive inmerso en él y con frecuencia debe extremar su cautela o su sabiduría administrativa para que éste no le devore. A los fenómenos tecnológicos, económicos, de formas institucionales (de especial relevancia por la descentralización operada en España) y de cambios de valores han de añadirse los específicamente públicos, donde los valores claramente profesionales o de establecimiento de valores propiamente directivos no han tenido especial apoyo.

Numerosos autores han tratado de la especificidad de la función directiva y en especial de la gestión pública, destacan- 
do la sustitución del mercado por el proceso político, la condición de poderes públicos de las Administraciones Públicas y otros como características relevantes del trabajo interno en las AAPP. Pero ello no nos debe llevar a sacralizar la distancia entre lo público y lo privado, sino a aprovechar las experiencias que el sector empresarial nos proporciona, si es preciso con adaptaciones ${ }^{39}$. El programa norteamericano de la Reinvención del gobiemo que lidera Al Gore y el propio libro de éxito del mismo nombre de OSBORNE y GAEBLER tienen el criterio de aprender de las empresas "como fundamental vehículo de innovación y progreso de las Administraciones Públicas.

No obstante, la tendencia a ponernos la venda antes de que tengamos la herida ha sido, casi siempre, una querencia de los directivos públicos: las técnicas de management se acompañan siempre cie la frase y usu necesaria adaptación a la especificidad del ámbito público" o los análisis en materia de personal ${ }^{40}$ deslacan de inmediato la imposibilidad de comparar los ámbitos públicos y privados.

Creo que establecer las diferencias es bueno y necesario, y ésta es la octava idea, pero debemos trabajar para lograr constituir una materia analítica suficiente que incorpore las mejores prácticas externas, sean éstas públicas o privadas, puesto que continuar dándole vueltas a nuestro proceloso mundo generará sin duda expertos cada vez más sutiles, pero escasos resultados de gestión. Una de las características que la actualidad parece exigir de los directivos públicos es probablemente en el ámbito del pensamiento sistémico y de la visión global la de gestionar lo interno, como contraposición a legislar hasta el infinito sobre la variedad de las situaciones administrativas de los funcionarios.

La rutina en el funcionamiento de las organizaciones es la línea de menor resistencia, aquella con la que transigimos tras algún intento innovador. Es más difícil modificar los usos, los procedimientos, que crear unos nuevos basados en otros principios. Puede afirmarse frente al aluvión de expertos foráneos que de inmediato, en ocasiones pronosticando soluciones temporales brevísimas, intentar arreglar los procedimientos de un servicio administrativo, que los mejores expertos están en la propia administración. El problema está, con seguridad, en los limites, especialmente plazos y competencias, que generan marañas organizativas de las que es difícil salir sin la ayuda de algún lazarillo ${ }^{4 !}$.

\section{Conclusión}

La cultura tradicional, a pesar de CROzIER, ha primado siempre a los funcionarios aalexitímicos ${ }^{42}$, en los que la pasión y, con demasiada frecuencia la ilusión, están fuera de sus prioridades. El perfil preferido para la organización tradicional, y para el alto responsable político, es el de quien antepone la seguridad a la creatividad, la experiencia a la innovación. Puede decirse, incluso, que tales características sirven en supuestos normales, habituales, pero constituyen una rémora importante cuando las circunstancias exigen decisiones o propuestas fuera de lo común.

El director de recursos humanos de Microsoft, Mike Creamer, se declara partidario de contratar únicamente a gente smart: personas inteligentes, creativas, flexibles, dinámicas, que puedan cambiar con la empresa. Este elemento del cambio continuo, a veces no tan acusado a primera vista en las organizaciones públicas, es especialmente importante, porque la atención a las condiciones externas constituye uno de los requisitos del éxito en la elaboración de las propuestas de decisión. Al fin y al cabo, la elaboración de las políticas públicas tiene más que ver con un análisis preciso de las condiciones del entorno.que con la aplicación ciega de la normativa.

En definitiva, un camino lleno de dificultades que destierre del sentir general frases como las que hace unos meses el Presidente de Argentina pronunció: «Un gobierno de cambios como el nuestro no puede ir deteniéndose a cada paso en la burocracia ${ }^{43}$. Desde otro punto de vista, Michel Crozier es crítico con nuestro tradicional sistema burocrático cuando señala que desprués de que la burocracia se vio en la necesidad de dictar cada vez más reglas para controlar la complejidad, el respeto por las mismas ba declinado y el sistema ba generado confusión e irresponsabilidad.

Sobre el asunto, el vicepresidente de los Estados Unidos, A] Gore, que lidera el Programa de la Reinvención del Gobierno, ha sido aún más drástico al afirmar que agran parte de lo que llamamos gestión consiste en dificultar el trabajo de la gente. Esta frase, no exenta de dureza para quienes desempeñan sus actividades en las organizaciones públicas, es sin embargo un reflejo ciertamente aproximado de la opinión pública.

Probablemente, las leyes ordenan la sucesión de trámites y controles, y los servidores públicos, sobre todo y en primer lugar, han de cumplir con ellas. Sin embargo, ba de bacerse un esfuerzo de mejorar y éste podria empezar con una regulación legal exbaustiva de los directivos públicos. Ésta es la novena idea.

En nuestro país, no son aplicables, como tampoco lo son ya a los EE.UU., las palabras de Andrew Jackson, presidente estadounidense paradigmático para los partidarios del spoil system: los trabajos confiados a los agentes del Estado son tan fáciles que todo bombre inteligente puede adaptarse a ellos sin demora. Siguen en mi opinión, sin embargo, vigentes aquellas referencias del Estatuto General de la Función Pública de 1852, que advertía que el Gobierno no debía ejercer la potestad de nombrar a los funcionarios públicos de su confianza para la particular conveniencian sino que ayer y hoy hemos de abuscar cuidadosamente las personas más a propósito para el desempeño de cargos públicos. 
En el mundo de hoy, el desarrollo de actividades relacionadas con el fomento de las habilidades interpersonales de los colaboradores, la solución de conflictos, la obtención de los mejores recursos para la organización en el marco de una negociación continua con otros directivos que realizan actividades similares, son las auténticas tareas del directivo. Contar con los colaboradores en el establecimiento de la mejor solución es cada vez más no tanto un ejercicio de posiciones democráticas ${ }^{44}$ por parte de los directivos sino también de aprovechamiento de las capacidades de otros. Es ésta la filosofía que impregna las teorías que, procedentes del otro lado del Atlántico, y desde hace pocos años, se denomina empowerment ${ }^{45}$.

Precisamente, una manifestación práctica de este tipo de conductas puede encontrarse en el Programa de Reinvención del Gobierno norteamericano. Al analizar las experiencias más recientes, Gore realiza una apuesta por quienes desarrollan su actividad profesional en la Administración norteamericana: sla energía y la creatividad que alientan la reinvención del gobier- no, han emanado de los propios funcionarios federales. Nadie mejor que ellos para saber qué va mal con el Gobiemo ni mejor dispuesto a enmendarlo. ${ }^{46}$.

La décima idea es llamar la atención sobre la necesidad de desarrollar en las Administraciones Públicas actividades de empowerment, de responsabilidad y delegación es una necesidad que debe abarcar a todas las onganizaciones y alcanzar a todas las personas que desarrollan actividades directivas. El obligado cumplimiento de las normas jurídicas que deben abrazar todo el trabajo de los directivos públicos, no justifica la imposición de controles excesivos y sucesivos que en nada favorecen el cumplimiento del servicio público y la obligación ética de cumplirlo responsable y eficazmente.

Llego al final del artículo y no puedo evitar pensar, quizás para sorprender una vez más, que, como Luis LANDERO, «estoy a punto de decir algo, pero noto que no hago pie ni en la sensación ni en las palabras, y me sale sólo un balbuceo de náufra$\mathrm{gO}^{47}$.

\begin{abstract}
Administrador Civil del Estado. Profesor Asociado de la Universidad Carlos III de Madrid.

1 De hecho, otra de las corrientes más importantes en el ámbito de la gestión, la reingeniería de procesos, tiene su principal fundamento en Frederick Winslow TAYLOR y, especialmente, en su libro The principles of scientific management de 1911. ....la reingeniería de la década de 1990 es sencillamente taylorismo de finales del siglo XX. Aunque el enfoque de la reingeniería se centra en el proceso, que no en la tarea individual, la motivación es la misma: simplificar, eliminar los esfuerzos innecesarios, y hacer más con menos. Gary Hamel. Citado por Stuat Crainer en rlos 50 mejores libros de gestión empresarial. Deusto, 1998.
\end{abstract}

- Un análisis pormenorizado de la repercusión editorial en todos los paises de la OCDE del libro de Daniel Golemaiv La inteligencia emocional, que contiene aspectos interesantes para nuestra materia, podría confirmar la existencia de lecturas universales. Similar conclusión puede extraerse de En busca de la excelencia de PETERS y WATERMAN o de La reinuención del Gobierno de OSBORVE y GAEBLER.

\footnotetext{
3 Los cambios producidos en nuestras sociedades han sido objeto de una enumeración y valoración especial entre nosotros por Enrique GUERRERO: ·a aparición de las tecnologias de la información que inciden transversalmente sobre todos los procesos productivos, asi como sobre la organización del trabajo; su impacto sobre la configuración de los actores sociales y sobre la fụnción de los sujetos políticos tradicionales; el riesgo de incompatibilidad del modelo de desarrollo dominante con la preservación del medio natural; los avances de la genética que permiten incrementar la producción, intervenir en la enfermedad, revolucionar la reproducción y alterar las estructuras familiares; el alargamiento de la esperanza de vida y sus repercusiones sobre las estructuras y las pautas sociales, los períodos laborales activos, las prestaciones sociales, la financiación de las mismas; la mayor plumalidad y diferenciación social; la aparición de nuevas formas de marginación, la pujanza de las migraciones y la creciente conformación de mosaicos culturales o de culturas de mestizaje; la globalización de los procesos financieros, producivos, etc., pero no de los mecanismos de toma o de control de las decisiones; la precarización de los límites fronterizos y la dificil pervivencia de las normas territoriales reducidas; : la dificultad de concretar y hacer extensivos los consensos sociales; el desarrollo de la comunicaçión que posibilita la amplitud, extensión e inmediatez de la información, pero que tiene asimismo la capacidad de interferir entre gobiemo y ciudadanos, representantes y ciudadanos, gobiemo y representantes, etc.. -Control parlamentario, El caso de España. Tesis Doctoral. UCM. Madrid, 1998.
}

1 Alain TOURANE señala que la globalización es un proceso de diferenciación de varias dimensiones de la vida colectiva, y lo hace depender de varios factores cuya aparición ha determinado la vida colectiva en los últimos años: •... aumento del comercio mundial y más peso de las empresas transnacionales, ... desartollo tremendo de las redes del capital financiero,... la sociedad de la información o de la comunicación, ... formación de nuevos paises industriales, y ... la hegemonia de los Estados Unidos en el terreno militar y cultural. Alain Touralve. Diario 16, 4 de octubre de 1998. La globalización ha sido también objeto de análisis desde otros puntos de vista. Eugenio Trías (El Mundo, 22 de septiembre de 1998) indica que la globalización significa dejación de soberania del Estado-Nación en muchos dominios importantes; sobre todo en el más sensible a cambıos e inceridumbres en el mundo contemporáneo: el económicor. Por su parte, Robert J. SAMUELSON profeciza el fin de la globalización: dos tambaleantes mercados de valores mundiales contienen un mensaje: el capitalismo gobal -cuyo triunfo pareció inevitable- está en plena retirada, quizá para muchos años.

" Algunas de ellas deberán tener como fin lograr una mayor adecuación entre los servicios prestados y las demandas ciudadanas. OSBORVE y GAEBLER en 1993 llamaron la atención sobre la continua demanda ciudadana o de los aclientes. por la mejora de los servicios y desde numerosos campos se llama la atención (OCDE, Banco Mundial) sobre la contradicción existente entre el incremento de demanda de nuevos servicios y la necesidad de contener el déficit público. Esta cuestión, entre otras, lleva a que la distancia entre las Administraciones Públicas y la sociedad (y especialmente entre los empleados públicos y la sociedad) se acreciente.

"La proposición francesa, enviada en un memorándum a los ministros de Hacienda de los Quince el día 23 de septiembre de 1998 propone una actuación común para reforzar el Fondo Monetario Internacional y limitar el flujo de capitales desestabilizadores. En el mismo sentido es posible encontrar declamciones del Presidente de los Estados Unidos Bill Clinton o del Primer Ministro del Reino Unido que ha insistido en la •necesidad de construir un nuevo Bretton Woods para el próximo milenio.

' ... hasta los casinos tienen normas para entrar en ellos y el mundo siente hoy en una coyuntura complicada la necesidad de ser dirigido por aquellos a los que se elige, no por los hechiceros económicos que juegan al póquer del mentiroso. Sólo encontrando un new deal, un nuevo pacto, se podrá evitar la inestabilidad de este tiempo, pern también el daño de volver a un pasado proteccionista, del que emerja una especie de contraideología del pensamiento único, igual o más peligrosa que éste.... Joaquín EsTEFANIA. El País, 6 de octubre de 1998. 
En su ensayo La Tercera Via, Tony Blalr destaca aspectos como éstos: •con demasiada frecuencia, la calidad se pasaba por alto. La política de Best Value del Nueto Laborismo exige constantes mejoras en la prestación... Da prioridad a los usuarios de los servicios y bace gran énfasis en la competencia, pero la utiliza como un medio y no como un fin...El Best Value bace que el sector püblico cobre mayor protagonismo pero alienta la cooperación de los sectores puiblico y privado. La Tercera Via. Madrid, 1998.

${ }^{9}$ CASTELLS y Borja definen la sociedad de flujos como una sociedad en la que la base material de todos los procesos está becha de flujos, en la que el poder y la riqueza están organizados en redes globales por los que circulan flujos de información ... flujos financieros, flujos de tecnologia, flujos de creación de imagen, .... Local y Global. Jordi BorJa y Manuel CASTELLS. Madrid, 1997.

li" Francisco AYAla lo ha expresado con nitidez: .Pues es el caso que este mundo de todos ba llegado en nuestros dias a ser tan complejo, tan cambiante y tan confuso que, a decir verdad, induce a incertidumbre y más bien invitaria a una muda perplejidad. -Ante el desconcierto de la cultura. El País, 24X-98.

"En opinión de BORJa y CASTELLS los gobiemos locales ... gozan de mucha más flexibilidad, adaptabilidad y capacidad de maniobra en un mundo de flujos entrelazados, demandas y ofertas cambiantes y sistemas tecnológicos descentralizados e interactivos. Local y Global, 19.

12. El dato de la heterogeneidad de los intereses públicos, si ya era posible detectarlo en el seno de una única Administración Pública, se ha visto acrecentado por el pluralismo político territorial, que ve con naturalidad que un mismo interés público, declarado por el legislador nacional, pueda ser desarrollado normativamente y gestionado en base a distintas opciones políticas, según el resultado de representación política de cada comunidad territorial. Luis ORTEGA. .La modemización de las Administraciones Públicas. GAPP n. ${ }^{\circ}$ 56, 1996.

13. .La interdependencia, el conflicto, la existencia de un grado irreductible de discrecionalidad y autonomía en las organizaciones, las dificultades y los costes de ejecutar y controlar las órdenes, asi como la presencia de información descentralizada y amplia necesaria, incluso para formular muchas órdenes han llevado a muchos analistas de las organizaciones a clasificar el mandato como solo uno -aunique importantede los numerosos medios de influir sobre los demás. David A. LAX y James K. SEBENIUS, El directivo como negociador. Instituto de Estudios Fiscales, Madrid, 1991.

11 Bien es verdad que HeRTzBerg es conocido también por haber inventado el acrónimo KITA (Kick in the ass. patada en el culo): si usted tiene a alguien en un puesto de trabajo, utilícelo. Si no puede utilizarlo, deshágase de èl. Lejos de mi intención tratar ahora este tema cuya aplicación en una organización pública requeriria una reflexión mucho más profunda.

1: Refiriéndose a los ingenieros dè obras públicas franceses destinados en la periferia, estos autores afirman: • En caso necesario, no dudan de emplear este poder para presionar a sus superiones jerárquicos y para robustecer su posición de negociación. A través de estas relaciones, diversas partes del entorno pueden interferir con los procesos intermos de la administración, baciendo confusa y arbitraria la delimitación juridica entre los asuntos internos y externos. Jean Claude THOENIG y Erhard FRIEDBERG. La influencia del personal desconcentrado geográficamente. El caso del Ministerio de Obras Públicas, Asuntos Urbanos y Vivienda, de Francia. Cómo reformar la Administración Pública. FCE México, 1977.

16 DE VRIES. La Conducta del Directivo.

${ }^{17}$ De las acepciones que de esta palabra recoge el Diccionario de Uso del español de Maŕa MOLNER, utilizamos la segunda: documento legal en que se contiene un acuerdo. En mi opinión, la situación ideal pasaría por la determinación explícita de la relación, es decir, por la plasmación normativa, específica, de los directivos públicos.

${ }^{18}$ Sobre la importancia y complejidad de la actuación de los gobiemos locales con frecuencia olvidados de nuestra reflexión, conviene tener en cuenta, como ha expresado fielmente Francisco J. VANACLOCHA, el inctemento de su papel en las políticas públicas en los últimos años y su condición de actor de las políticas públicas y de -estructura con un papel central en el despliegue de las políticas públicas que responden directamente al respectivo ámbito de problemas. Identidad de los gobiemos locales y reforma electoral. El Sistema politico local: Un nuevo escenario de gobiemo. Edición a cargo de Carlos R. Alba y Francisco J. Vanaclocha (Vanaclocha, 276).

19 Recientes aporaciones en el campo del análisis de las políicas públicas enfatizan una concepción coincidente. GOMA y SUBIRATS señalan que se va configurando un escenario en el que, desde el campo del management en sentido genérico, se achacan a veces, implicita o explícitamente, los problemas de la gestión de las políticas públicas a la política. Se conviente en "irracional" o "pemicioso" lo que tiene que ver con la política, y en "racional" o "positivo" lo que tiene que ver con la gestión. Políticas Püblicas en España. Ricard Gomá y Joan SuBiraTs. Barcelona, 1998.

3) Jiménez Asensio en su libro Altos Cargos y Directivos Públicas trata extensamente el tema, reclamando la constitucionalidad de tal opción.

" En su presentación del Informe, Lord Nolan pone de manifiesto algunos de los poblemos que más tarde desarrolla: :... los cambios sucedidos en los últimos años con respecto a las funciones y entornos laborales de políticos y funcionarios han causado confusión acerca de lo que es una conducta aceptable o no. Esto, acompañado por cierto número de incidentes que han recibido mucha publicidad y que indican cierta negligencia en el cumplimiento y la ejecución de unas normas estrictas.por parte de los involucrados, ha contribuido a crear la sospecha generalizada de que los casos de mala conducta son más frecuentes que los que se revelan al público. Informe Nolan. Documentos INAP, Madrid, 1996.

" Bernard KLISBERG que ha estudiado con detenimiento los avatares de las burocracias públicas en el área latinoamericana se manifiesta favorable a la especificidad de la gerencia pública y al mismo tiempo de superar la antinomia entre políticos y altos funcionarios: da antinomia usual en la región (se refiere a Latinoamérica) constituye pues una trampa paralizante. No es resoluble en los términos en que está planteada dado que se requiere no una solución que elimine uno de sus componentes: el politico o el técnico, sino una salida que logre sintetizarlos. Genencia priblica en tiempos de incertidumbre. Madrid, INAP, 1989.

23 Alberto Gutiérrez Reñón, un administrador superior ya fallecido me refirió una anécdota que personalmente le ocurrió en Guatemala con ocasión de un Programa de Cooperación. Las dificultades orográficas de un territorio situado alrededor de un lago obligaban al inspector de educación a recorrerlo a caballo semanalmente, de forma que cada día visitaba un pueblo, sin poder regresar a su domicilio más que los fines de semana. Como experto, propuso la compra de un pequeño barco con motor y quedó encargado de convencer a las autoridades del Ministerio para que el asunto fuera incluido en el Presupuesto. Cinco años más tarde, regresó al pueblo y preguntó por el barco. Le dijeron que ya tenían cinco, que cada año tenían un barco nuevo, puesto que ya estaba incluido en el presupuesto.

"CAIDEN, señalando las habilidades y características necesarias a las personas que ejercen algún tipo de liderazgo en procesos de reforma administrativa, refiere que - Las condiciones necesarias incluyen una masa crítica de individuos dispuestos a la reforma, atentos a nuevas ideas, listos para articular y promover reformas, con antecedentes en diversas experiencias organizacionales y satisfechos por las innovaciones continuas. Estos líderes de la reforma deben poseer una inteligencia adiestrada, algunas cualidades (tales como una devoción por el desarrollo humano, propensión a la organización, espiritu de experimentación) y una imagen relativista. Gerald E. CNDEN, la implantación, talón de Aquiles de la Reforma administrativa, en Cómo reformar la Administración Pública. Compilador A.F. Leemans. México FCE, 1977.

3 Así lo manifiesta KaMto - La obsesión de los costes financieros de la administración ha traído consigo por todas partes la puesta en marcha -de importantes reformas administrativas que se dirigen a menudo únicamente hacia la reducción de efectivos a causa de la reducción de los cargos. Esta solución standárd preconizada por las instituciones de Bretton Woods no es adecuada para todos los casos incluso aunque no se pueda negar que los efectivos sean abundantes en casi todas las administraciones de los paises subdesartollados. Maurice KaMTO, Reaffirmation des valeurs et du professionalisme de l'administration. Retue Intermational des Sciences Administratives, vol. 63-1997.

${ }^{3}$ Sobre los diversos factores del entomo que pueden influir en el trabajo del directivo, MinTzBerg destaca la cultura del medio, la naturaleza del sector, una serie de factores dinámicos como pueden ser la competencia, el ritmo de cambio y los tipos de tecnología, así como las características de la organización en sí, incluidas su antigüedad y su envergadura. La Naturaleza del trabajo directivo. Henry MiNTZBERG, 143, Madrid, 1983.

"Estoy enfermo, dijo don Jasé, no puedo ir a trabajar. El colega se levantó contrariado, dio tres pasos en dirección al oficial de su sección, y lo informó, Disculpe, señor, abi está don José diciendo que se encuentra enfermo. Antes de dar los cinco pasos que lo separaban de la mesa del conservador, el subdirector se acercó a aveniguar la naturaleza de la enfermedad. . I José Saramago. Todos los nombres. Madrid, 1997.

\$ En su conocido ensayo le phénomène bureaucratique, CROzIER escribía en 1964 que el sistema de organización burocrático es incapaz de corregirse en función de sus etrores, dando lugar con ello a un tipo de acción administmativa excesivamente rígida y 
limitada, impermeable a las reacciones del medio al que se adapta con retraso tras largas y penosas desviaciones.

"En noviembre de 1998, el Gobiemo en respuesta a una pregunta parlamentaria de la oposición señaló la existencia de 11.123 funcionarios directivos: 8.535 de niveles 28, 29 y 30: 2.588 de niveles 27 (La Razón, 9-11-98).

"El escritor A. MuNOz Mouni ha reflejado con claridad en un arículo periodistico esta situación: - Yo creia que esas caras y esos modales babian desaparecido; esa complacencia en negar, en postergar, en ejercer sobre el ciudadano comun la autoridad infima de un uniforme... (El Pais, 27 de septiëmbre de 1998). En el mismo periódico Félix DE AZÚA, criticando la información meteorológica de TVE, afirma que el presentador utiliza el puntero con monotonia funcionarial sobre un retablillo barroco. $(30$ - de septiembre de 1998). La lista podría ser interminable.

"La Exposición de Motivos de la Ley señala como una de las más importantes enseñanzas ... la de la necesidad de garantizar plenamente la transparencia de la contratación administrativa como medio para lograr la objetividad de la actividad administrativa y el respeto a los principios de igualdad, no-discriminación y libre concurrencia.... Menor énfasis tienen en la citada Exposición las referencias a tla simplificación del procedimiento jurídico administrativo de contratación, suprimiendo algunos trámites que se han considerado menos necesarios....

3: Miguel SÁNCHEZ MORÓn ha descrito con claridad las diferencias entre los dirigentes y los dirigentes generales señalando que la reforma consiste en una privatización o laboralización de la relación de servicio de los empleados priblicos. De este transcen dental cambio de régimen juridico sólo se libran, aparte los dirigentes generales, los jueces y Magistrados (ordinarios, administrativos y contables) los Fiscales y Abogados del Estado, el personal militar y las fuerzas de policia y el personal de las carreras diplomática y prefectoral a pantir respectivamente de la categoria de Secretario de Legación y Viceconsejero de Prefectura. Todos estos funcionarios siguen sometidos a un régimen estatutario de Derecho puiblica. Sobre la Reforma Administrativa italiana del periodo de transición. Documentación Administrativa, n. 134.

\section{" STC 99/87 de 11 de junio.}

"... la combinación de principios gerenciales y burocráticos deberá variar de acuerdo con el sector. La gran cualidad de la administración pública burocrática es su seguridad y efectividad. Por lo tanto, en el núcleo estratégico, donde esas características son muy importantes, ella deberá estar todavía presente en conjunto con la administración pública gerencial. Ya en los demás sectores, donde el requisito de eficiencia es fundamental dado el gran número de empleados y de ciudadanos-clientes o usuarios involucrados, el peso de la administración pública burocrática deberá ir disminuyendo hasta que prácticamente desaparezca en el sector de las empresas estatales. . De la Administración pública burocrática a la gerencial. Luis Carlos BRES SER. Documentos Debate. CLAD, 1996.

is J. Prats lo ha expuesto convincentemente en un artículo que no tiene, en mi opinión, aplicación sólo en aquellos países sometidos a alteraciones profundas relacionadas con su nivel de desarrollo, sino también en España: •... la función puiblica como institución o sistema funcionarial de mérito, por la funcionalidad social que cumple, tiene un ámbito fundamental pero limitado dentro del sector priblico. Dicho ámbito se corresponde con las viejas funciones de soberania, autoridad o intervención administrativa, dinámicamente interpretadas o coincidentes boy con lo que otros au tores llaman funciones estatales de orden superior, núcleo estratégico of funciones exclusivas del Estado para la provisión de bienes priblicos propios. J. PraTs. Servicio Civil y Gobemabilidad democrática. Revista Iberoamericana de Administración Públi ca, n. ${ }^{2}$ l. Madrid, 1998.

*" Partiendo de coordenadas diferentes, M. VILORIa indica que sobre la base de la Encuesta Delphi, realizada en la Administración espanola en 1991 bajo la dirección de Javier VALERO, ‘que los conocimientos obtenidos y demostrados en el proceso selectivo para ingresar en Cuerpos no garantizan conocimientos y habilidades directivas. Lo cual implica:

- Hay que formar especificamente a los directivos.

- Hay que seleccionarlos éspecíficamente.

Manuel VILLORIA: -La función directiva en las Administraciones Públicas. en Manual de Gestión de Recursos Humanos de las Administraciones Püblicas. Madrid, 1997.
5 Cortina, refinéndose a los valores de una empresa postaylorista y, en particular a las empresas de la excelencia (en el sentido de PETERS y WaTERMav), "indica que dlös ideales comparidos reemplazan a la coerción burocrática, por eso no bastan las transformaciones intemas ni las promociones internas, sino que hay que cambiar las mentalidades, modificar la relación del individuo consigo mismo y con el grupo, pro-

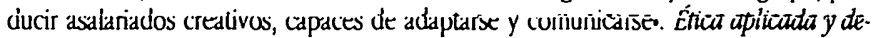
mocracia radical. Madrid, 1993 (27)

La coincidencia en que las personas son de nuevo el centro de atención universal es para Helmut KLAGES producto de las reflexiones sobre las causas de las crisis económicas y sobre las posibilidades de su finalización. que than convertido al personal de las organizaciones en el centro de atención. Modemización de la Administración: aspectos duros. y blandos. Documentos INAP, n. 17.

"No creo que deban ser tantas las adaptaciones que finalmente sea imposible reconocer el producto original. La tendencia a considerarlas como una nueva moda es evidente por pane de los funcionarios, incluyendo a los altos funcionarios. Describiendo la experiencia anglononeamericana del -gerencialismor, Pourt indica que .las mayores influencias del "gerencialismo" se han producido en los terrenos retórico y estilistico. Por lo menos, ahora los funcionarios se sienten obligados a utilizar términos como "objetivos", "planes de acción", "mejora de costes", "oportunidades para la generación de ingresos" y un largo etcétera más..., incluso cuando su afinidad por estos términos sea únicamente oportunista o superficial.... El Gerencialismo y los servicios priblicas. Christopher Pourt. Instituto de Estudios Fiscales, Madrid, 1993.

*" En un interesante arículo sobre planificación de recursos humanos en la Administración general del Estado, CATALÁ, ORDOZGOIT y MORENo indican refiriéndose a los mecanismos de planificación de los recursos humanos en el sector privado que son - dificilmente un instrumento eficaz sin la imprescindible adaptación de su lógica interna a una organización como la Administración, basada en presupuestos teóricos radicalmente distintos y sujeta a unos condicionantes propios de una Función Pública profesional y dotada de la imparcialidad necesaria para administrar el interés general. Planificación de recursos humanos en la Administración General del Estado: situación actual y líneas de futuro. GAPP, n. ${ }^{9}$. Madrid, 1997.

"El problema es tan habitual en las organizaciones públicas como en las privadas. Lester ThuRow lo relata brillantemente: Para el subordinado, los costos carecen de importancia. Ni siquiera los calcula. Uno hace lo que el jefe ordena. En esencia, tanto los jefes como los subordinados están aprisionados por procedimientos operativos que crean un conjunto institucional de ciegos. L. THUROw. La Guerra del Siglo XXI. Buenos Aires, 1992

12 Kets DE VRIEs indica que esta palabra griega significa ninguna palabra para las emociones. Las personas a las que clasificamos como alexitimicos son individuos que no muestran ninguna pasión - personas que, ..., parece que no tienen sangre en sus venas. La Conducta del directivo. Deusto, 1996.

"El alcalde de la ciudad alemana de Pforzheim, Joachim BECKER, ha sido aún más directo en su apreciación negativa de los funcionarios: $\operatorname{los}$ empleados del sector público, después de haber sufrido cierta fatiga una única vez en su vida -aprobar una oposición cualquiera-, se sienten legitimados a acogerse al derecho de la vagancia de por vida. En Der erscböpfie Sozialstaat, p. 150. Citado por Helmut KLAGES. Documentos INAP, n.. 17. Madrid, 1998.

"B. KLISBERG indica que para América Latina, igualmente, se requieren gerentes que sean capaces de generar fenómenos de identificación con la organización y de participación en ella, es decir, dirigir democráticamente las organizaciones. Gerencia pública en tiempos de incertidumbre. Madrid. INAP, 1989.

"Ken BlanchaRd lo ha explicado a través de uno de sus libros de éxito de gestión novelada, en esta ocasión .El empowerment requiere más de un minuto: :En el marco del empotverment su nuevo papel como directivo es coordinar esfuerzos, obtener recursos, realizar la planificación estratégica, tratar con los clientes, asesorar y apoyar al personal, y actividades similares. Todo lo que uno hace es para ayudar a que su personal sea más eficaz. Ahora usted trabaja para ellos en lugar de que ellos trabajen para usted.

* Para una visión de las últimas actuaciones del gobierno norteamericano puede consultarse Gobemar con criterio empresarial. Lecciones aprendidas de las mejores compañias de América. Al Gore. Documentos INAP, n. 16.

"Un hombre de acción. Luis Lavdero. El País, 1-11-98. 


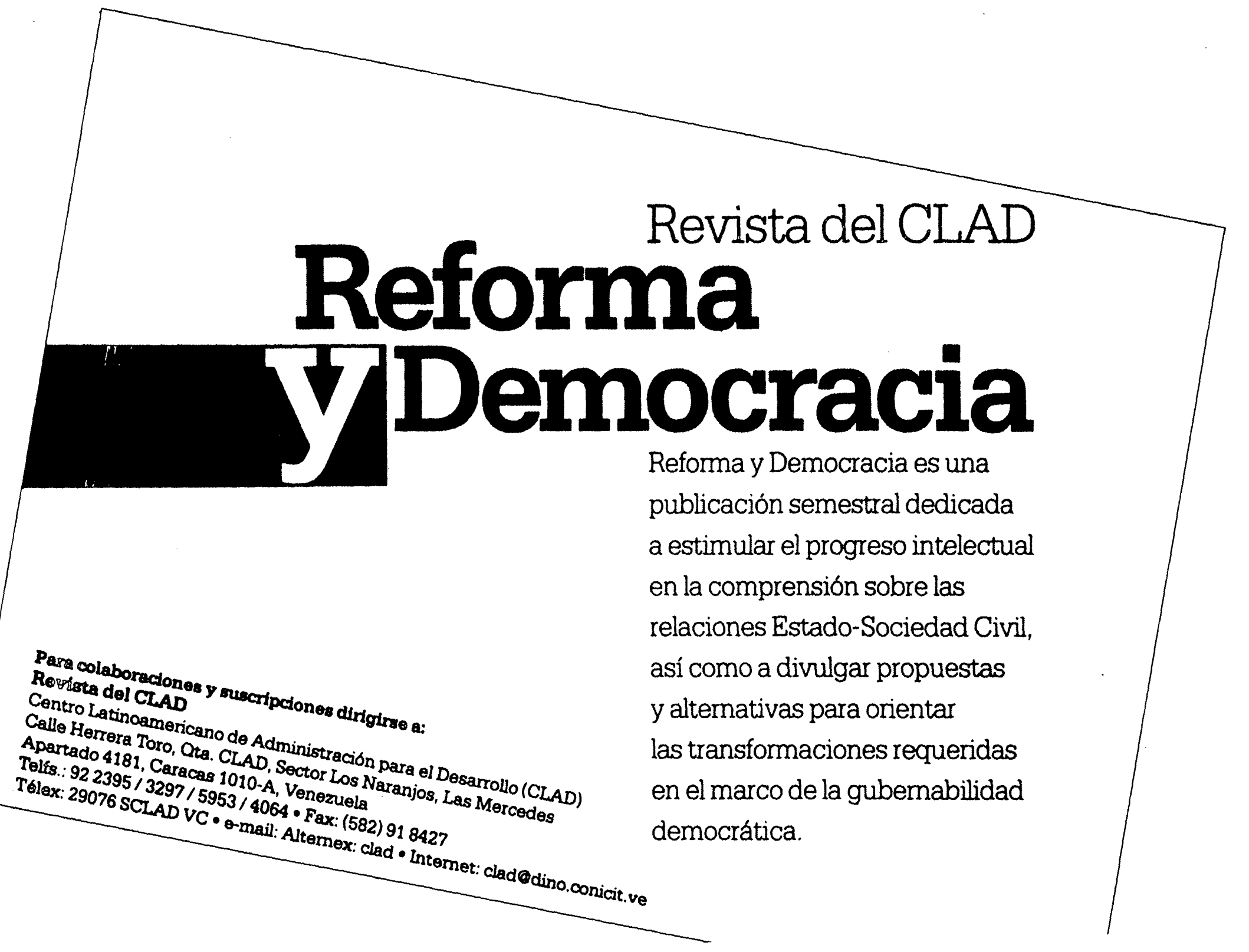

